\title{
Green competitiveness research on Chinese automotive enterprises
}

\author{
Yuanhui Li \\ School of Economics and Management, Beijing Jiaotong University (China) \\ ybli@,bjtu.edu.cn
}

\section{Abstract:}

Purpose: More and more executives of automobile industry in China start to recognize the concept of green competitiveness recently. However, relatively less research attention has been devoted to the consideration of measurement. This paper aims to find empirical approach to quantify green competitiveness for automotive enterprises. The connotation of green competitiveness is explored and one suite of evaluation index system has been proposed with four dimensions including environmental, resource, capability and knowledge.

Design/methodology/approach: By introducing the factor analysis method, green competitiveness has been measured through an empirical analysis of 24 automotive enterprises within China.

Findings: The results indicate that those elements, such as enterprise resource possession and utilization; environment, responsibility and knowledge; profitability; management efficiency, have significant effect on the green competitiveness for automotive enterprises. The further analysis also unveils the advantages and disadvantages of green competitiveness for each company and the direction for improvement.

Research limitations/implications: Guide regulators and managers of automobile industry to take some measures to enhance their green competitive advantage.

Practical implications: Provide practical methods to measure green competitiveness for automotive enterprises. 
Originality/value: This paper proposes an evaluation index system of green competitiveness for automotive enterprises. The suggestions of our research will be beneficial to enterprise executives and industry regulators.

Keywords: automotive enterprises; green competitiveness; competitiveness evaluation

\section{Introduction}

Green competitiveness was first proposed by Porter in 1991. The contradiction between environment and competitiveness would disappear after stringent environmental standards encouraged company's innovation (Porter, 1991). Managers must start to recognize environmental improvement as an economic and competitive opportunity, not as an annoying cost or an inevitable threat (Porter, 1995a). Making an empirical examination of the relationship between emission reduction and firm performance, Hart and Ahuja (1995) find that it does indeed pay to be green, efforts to reduce emissions through pollution prevention appear to drop to the bottom line within one to two years after initiation and that those firms with the highest emission levels stand the most to gain. Russo and Paul (1997) verify environmental performance and economic performance are positively linked and that this relationship strengthens with industry growth with an analysis of 243 Firms over two years.

The automobile industry is one of the most important foundations of national economy which can represent the national core competitiveness. China has already become the biggest automobile manufacturer and the largest market in the world. However, from the resource and environmental perspective, China is still far below those advanced countries like German, Japan and US. It is no doubt that low carbon economy is the latest trend of the global economy development. And it is the only choice for China to accelerate the transformation of economic development mode and to take a new industrialization approach in order to achieve the sustainable growth in both economic and social development. The key challenge for China automobile enterprises is how to adjust their development strategy so as to find the industrial upgrade path of advanced technology, more economic, lower resources consumption and less environmental pollution (Li \& Ding, 2009). Based on such background, this paper attempts to focus on the research on green competitiveness of China automobile enterprises.

The remainder of this paper is organized as follows. The meaning of green competitiveness for automotive enterprises has been described in the next section. The following section proposes the evaluation index system. We then report the empirical analyses and findings followed by conclusions and implications of this study. 


\section{Analysis of green competitiveness for automotive enterprises}

\subsection{Connotation analysis}

In general, green competitiveness for business organizations is the capability to gain a competitive advantage of market share through value creation in terms of environment protection and social responsibility, which directs the company towards sustainable growth. Specifically, for an automotive company, the connotation of its green competitiveness should include the following attributes:

Automotive enterprises must realize that the environmental protection and corporate development are not competing against each other. Quite the contrary, those two could be harmonized to pursue sustainable development (Porter, 1995b).

Automotive enterprises must not only pursuit economic interests, but also should take the responsibility of environment and society. The contribution to consumers, environment and society must be taken into consideration by automotive enterprises.

Automotive enterprises can enhance green competitiveness by introducing sustainability and knowledge management into product lifecycle management to carry out innovation and to reduce CO2 emissions, materials and energy (Trotta, 2010). The implementation of various production elements should be configured with the supply chain based on environmental management so as to minimize the damage to environment and human health (Luthra, Kumar, Kumar \& Haleem, 2011).

\subsection{Dimension Analysis}

According to above analysis, elements of green competitiveness for automotive enterprises could be classified into four dimensions: environment; resource; capability; knowledge.

\subsubsection{Environment dimension}

Environment dimension is the set of the elements which are related to environmental responding capacity. Those elements run through the process of production and operation of the company, which can be measured by the investment of environmental protection and the implementation of its corporate social responsibility. 


\subsubsection{Resource dimension}

Resource dimension includes the elements which is the fundamental to the green competitiveness. The resource managed by the company is the cornerstone competing with others, which could dramatically affect the corporate operation (Wernerfelt, 1984). By the analysis on the characteristics of automotive enterprises competitiveness, resource dimension could be described by material resources, human resources and market resources.

\subsubsection{Capability dimension}

The green competitiveness for automotive enterprises depends not only on the ownership of resources, but also the resource utilization and development. Capability dimension is defined to describe the ability how the target company could have better performance in its operating activities than competitors with certain resources level. As this ability is not easy to be quantified directly, we can measure it according to its dominant performance, such as efficiency of resources usage, profitability and growth ability.

\subsubsection{Knowledge dimension}

Knowledge, or know-how, is the key factor supporting the automotive enterprise capabilities. It is the spirit of enterprise competitiveness. This is the top level competition for green competitiveness. Automotive enterprises can enhance green competitiveness dramatically through the creation of low-carbon automotive knowledge, which could help the company to differentiate against competitors by taking advantage of customer environmental preference. Knowledge itself differs from material, human and market resources. It is difficult to be observed directly so we have to describe it by measuring the input and output of automotive enterprises in the process of knowledge creation. With this approach, the investment in R\&D and the quantity and quality of patents can represent the level of knowledge creation.

The interrelations among the four dimensions that facilitate green competitiveness improvement can be shown in Figure.1. Those four dimensions are not separately running by themselves while they are tightly connected and correlated with each other during the entire enterprise cycle. We realize that there are two paths among those dimensions as demonstrated in the figure, which could be represented by up-stream and down-stream. 


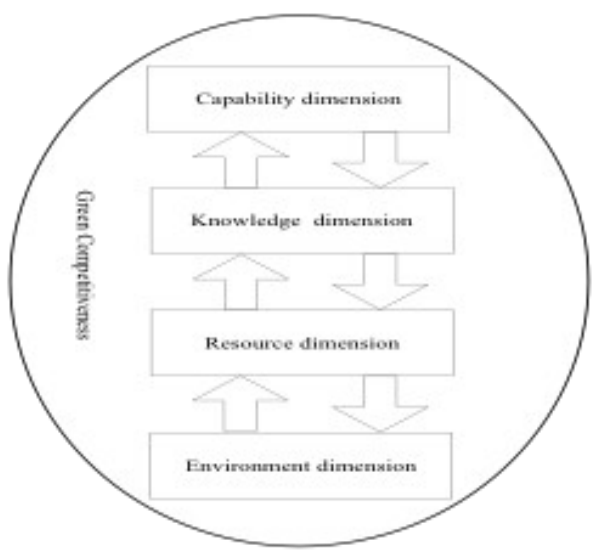

Figure 1. The interrelations among the four dimensions

For the up-stream from bottom to the top, a positive driven effect will be generated out from this path. The positive external environmental dimension will lead the automotive enterprise towards the strategy which could result in the enhancement of the competitiveness. Such effect will be transferred to the upper level for the required resources input. The knowledge dimension will be triggered whenever the scientist or key technologies are necessary. Those efforts will finally contribute to the upgrade of the green competitiveness through the capability dimension.

Looking into the down-stream from the reverse direction, the enterprise could then have the new request of the latest technologies once they have enhanced capability dimension with advanced solution. As the knowledge dimension has been enhanced through learning and innovation, those enhancement will again support the automotive enterprise for advanced resources accumulation. Consequently the higher level the upper dimensions could achieve, the better motivation and ability the enterprise will have to improve the environment as well as the environment factors.

In short, the up-stream will guarantee the normal cultivation of the green competitiveness while the down-stream will manage the transition to the higher level of the competitiveness. With the correlation between up and down-stream, a sustainable growth trend of green competitiveness could be formed for the enterprise.

\section{Construction of evaluation indicator system of green competitiveness for automotive enterprises}

Yuan, Wang and Chen (2009); Chen, Wang and Yin (2009); Chen, Liu and Yuan (2013) conduct methodology and empirical research on green competitiveness evaluation, but litter relevant to automotive companies. This section aims at formulate one general evaluation index 
structure of green competitiveness for automotive enterprises which is operational and comparable. Through such index structure, the enterprise could easily perform the benchmark from both horizontal and vertical approach. Based on such benchmark, the company could find its own position among the whole industry while its disadvantage could be identified. The enterprise could also understand the competitiveness development status during certain period. By the analysis towards the content and dimension of the green competitiveness for automotive enterprise, AHP method has been utilized for the sub-dimension decompose and indicators design for those dimensions such as environmental, resources, capability and knowledge. The details are shown in Table 1.

\begin{tabular}{|c|c|c|}
\hline Dimension & Elements & Indicators \\
\hline \multirow{6}{*}{ Environment } & $\begin{array}{l}\text { Environmental } \\
\text { protection }\end{array}$ & Ratio of environmental protection investment $\left(\mathrm{X}_{1}\right)$ \\
\hline & \multirow{5}{*}{ Responsibility } & Staff responsibility $\left(\mathrm{X}_{2}\right)$ \\
\hline & & Supplier responsibility $\left(\mathrm{X}_{3}\right)$ \\
\hline & & Shareholders responsibilities $\left(\mathrm{X}_{4}\right)$ \\
\hline & & Creditors responsibility $\left(X_{5}\right)$ \\
\hline & & Government responsibility $\left(\mathrm{X}_{6}\right)$ \\
\hline \multirow{6}{*}{ Resource } & \multirow{3}{*}{ Material resource } & Total assets $\left(X_{7}\right)$ \\
\hline & & Fixed assets $\left(\mathrm{X}_{8}\right)$ \\
\hline & & Intangible assets $\left(\mathrm{X}_{9}\right)$ \\
\hline & \multirow{2}{*}{ Human resource } & Total number of employees $\left(\mathrm{X}_{10}\right)$ \\
\hline & & The proportion of college education $\left(\mathrm{X}_{11}\right)$ \\
\hline & Market resource & Market share $\left(\mathrm{X}_{12}\right)$ \\
\hline \multirow{10}{*}{ Capability } & \multirow{4}{*}{ Resource use } & Labor productivity $\left(\mathrm{X}_{13}\right)$ \\
\hline & & Total assets turnover $\left(\mathrm{X}_{14}\right)$ \\
\hline & & Inventory Turnover $\left(\mathrm{X}_{15}\right)$ \\
\hline & & Accounts receivable turnover ratio $\left(\mathrm{X}_{16}\right)$ \\
\hline & \multirow{3}{*}{ Profitability } & Return on total assets $\left(\mathrm{X}_{17}\right)$ \\
\hline & & Return on equity $\left(X_{18}\right)$ \\
\hline & & Operating margin $\left(X_{19}\right)$ \\
\hline & \multirow{3}{*}{ Growth ability } & The growth rate of total assets $\left(X_{20}\right)$ \\
\hline & & Revenue growth $\left(X_{21}\right)$ \\
\hline & & Capital Maintenance and growth rate $\left(X_{22}\right)$ \\
\hline \multirow{4}{*}{ Knowledge } & \multirow{2}{*}{$\begin{array}{l}\text { Knowledge } \\
\text { development }\end{array}$} & $R \& D$ funds expenditure rate $\left(X_{23}\right)$ \\
\hline & & R \& D personnel proportion $\left(X_{24}\right)$ \\
\hline & \multirow{2}{*}{$\begin{array}{l}\text { Knowledge } \\
\text { outputs }\end{array}$} & Total number of patents $\left(X_{25}\right)$ \\
\hline & & Invention patent ratio $\left(X_{26}\right)$ \\
\hline
\end{tabular}

Table 1. Evaluation indicator system on green competitiveness of China Automotive enterprises

\section{Empirical analysis of green competitiveness for automotive enterprises}

Taking above index structure into practice, we manually collected the data of all 24 domestic automotive listed companies from Shenzhen and Shanghai Stock Exchange for detail analysis. The data collection is based on the information of year 2011. Factor analysis method has been used for empirical analysis. Seven factors has been found and named after such analysis. Among those seven factors, the analysis consequently reveals the factors like enterprise resource possession and utilization; environment, responsibility and knowledge; profitability; management efficiency, have a key effect on the green competitiveness for automotive enterprises. 


\subsection{Sample}

The sample includes 24 domestic auto listed companies which are Weichai Power, JMC, Haima, Changan, FAW Car, Ankai bus, Xiali, China National Heavy Duty Truck, Zhongtong Bus, BYD, DFAC, Yutong Bus, SAIC, Foton Motor, Dongan Power, Yaxing Bus, Shuguang, Xingma automobile, JAC, Dima, Jingbei, Jinglong, Zhonghang Heibao, Great Wall Motor. Related data come from listed companies 2011 annual report and social responsibility report as well as national relevant department's information disclosure, company web site and other information.

\subsection{Methodology}

Factor analysis is a method widely used to seek values of the loadings that bring the estimate of the total communality as close as possible to the total of the observed variances.

\subsubsection{Data standardization}

The raw data should be standardized calculation before variable analysis. Standard deviation standardized methods can be used, we can get a new matrix R according to Formula (1).

$$
r_{i j}=\frac{\sum_{k=1}^{n}\left(x_{k i}-\bar{x}_{i}\right)\left(x_{k j}-\bar{x}_{j}\right)}{\sqrt{\sum_{k=1}^{n}\left(x_{k i}-\bar{x}_{i}\right)^{2} \sum_{k=1}^{n}\left(x_{k j}-\bar{x}_{j}\right)^{2}}} \quad \text { (1) } \quad R=\left[\begin{array}{cccc}
r_{11} & r_{12} & \cdots & r_{1 p} \\
r_{21} & r_{22} & \cdots & r_{2 p} \\
\vdots & \vdots & \vdots & \vdots \\
r_{p 1} & r_{p 2} & \cdots & r_{p p}
\end{array}\right]
$$

\subsubsection{KMO and Bartlett test}

KMO test value is 0.723 , greater than 0.5 , indicating that the data is suitable for factor analysis. Bartlett test shows accompanied probability is 0.000 , less than the significance level of 0.05 . Therefore we can deny the null hypothesis of Bartlett test that is suitable for factor analysis.

\subsubsection{Structure factor variables}

Variance contribution rate and cumulative contribution rate can be calculated according the Formula (3), (4). Eigen values, variance contribution rate and cumulative contribution rate 
obtained by the calculation of the correlation coefficient matrix $\mathrm{R}$ are shown in Table 2 , in which the variance contribution rate reacts of the factors' the explanatory power to the total variance of all the original variables, so it is a measure of the importance of common factor, the higher the value, the higher the degree of importance of the common factor. Table 2 shows that variances of seven factors are $21.009 \% ; 18.667 \% ; 16.441 \% ; 11.556 \%$; $8.513 \%$; $5.801 \% ; 5.532 \%$ respectively. The cumulative variance contribution rate has reached $87.520 \%$, which means that the seven factors have been sufficient to describe the overall level. Therefore, we can carry on the follow-up factor analysis process.

$$
\frac{\lambda_{i}}{\sum_{k=1}^{p} \lambda_{k}} \quad(i=1,2, \cdots, p)
$$

$\lambda_{\mathrm{i}}$ : characteristic roots of correlation matrix

$$
\frac{\sum_{k=1}^{i} \lambda_{k}}{\sum_{k=1}^{p} \lambda_{k}} \quad(i=1,2, \cdots, p)
$$

\begin{tabular}{|c|c|c|c|c|c|c|c|c|c|}
\hline & \multicolumn{3}{|c|}{ Initial Eigen values } & \multicolumn{3}{|c|}{$\begin{array}{c}\text { Extraction Sums of Squared } \\
\text { Loadings }\end{array}$} & \multicolumn{3}{|c|}{$\begin{array}{c}\text { Rotation Sums of Squared } \\
\text { Loadings }\end{array}$} \\
\hline & Total & $\begin{array}{l}\% \text { of } \\
\text { Variance }\end{array}$ & $\begin{array}{c}\text { Cumulative } \\
\%\end{array}$ & Total & $\begin{array}{l}\% \text { of } \\
\text { Variance }\end{array}$ & $\begin{array}{c}\text { Cumulative } \\
\%\end{array}$ & Total & $\begin{array}{l}\% \text { of } \\
\text { Variance }\end{array}$ & $\begin{array}{c}\text { Cumulative } \\
\%\end{array}$ \\
\hline 1 & 6.824 & 26.247 & 26.247 & 6.824 & 26.247 & 26.247 & 5.462 & 21.009 & 21.009 \\
\hline 2 & 4.971 & 19.119 & 45.366 & 4.971 & 19.119 & 45.366 & 4.853 & 18.667 & 39.676 \\
\hline 3 & 3.765 & 14.479 & 59.845 & 3.765 & 14.479 & 59.845 & 4.275 & 16.441 & 56.118 \\
\hline 4 & 3.015 & 11.595 & 71.440 & 3.015 & 11.595 & 71.440 & 3.005 & 11.556 & 67.674 \\
\hline 5 & 1.817 & 6.989 & 78.429 & 1.817 & 6.989 & 78.429 & 2.213 & 8.513 & 76.187 \\
\hline 6 & 1.335 & 5.136 & 83.565 & 1.335 & 5.136 & 83.565 & 1.508 & 5.801 & 81.988 \\
\hline 7 & 1.028 & 3.955 & 87.520 & 1.028 & 3.955 & 87.520 & 1.438 & 5.532 & 87.520 \\
\hline 8 & .928 & 3.568 & 91.088 & & & & & & \\
\hline 9 & .516 & 1.984 & 93.072 & & & & & & \\
\hline 10 & .449 & 1.727 & 94.799 & & & & & & \\
\hline 11 & .330 & 1.269 & 96.068 & & & & & & \\
\hline 12 & .301 & 1.156 & 97.224 & & & & & & \\
\hline 13 & .241 & .926 & 98.150 & & & & & & \\
\hline 14 & .146 & .560 & 98.710 & & & & & & \\
\hline 15 & .130 & .499 & 99.209 & & & & & & \\
\hline 16 & .096 & .367 & 99.577 & & & & & & \\
\hline 17 & .039 & .150 & 99.727 & & & & & & \\
\hline 18 & .030 & .115 & 99.842 & & & & & & \\
\hline 19 & .021 & .080 & 99.921 & & & & & & \\
\hline 20 & .010 & .039 & 99.960 & & & & & & \\
\hline 21 & .006 & .024 & 99.984 & & & & & & \\
\hline 22 & .004 & .016 & 100.000 & & & & & & \\
\hline 23 & .000 & .000 & 100.000 & & & & & & \\
\hline 24 & .000 & .000 & 100.000 & & & & & & \\
\hline 25 & .000 & .000 & 100.000 & & & & & & \\
\hline 26 & .000 & .000 & 100.000 & & & & & & \\
\hline
\end{tabular}

Table 2. Variance explained 


\subsubsection{Factor loading}

According to the formula (5), we can calculating factor loading aij, then we can get loading matrix $A$.

$$
\begin{gathered}
a_{i j}=\sqrt{\lambda_{i}} l_{i j}(i, j=1,2, \cdots, p) \\
A=\left[\begin{array}{cccc}
a_{11} & a_{12} & \ldots & a_{1 m} \\
a_{21} & a_{21} & \ldots & a_{2 m} \\
\ldots & \ldots & \ldots & \ldots \\
a_{p 1} & a_{p 1} & \ldots & a_{p m}
\end{array}\right]=\left[\begin{array}{cccc}
l_{11} \sqrt{\lambda_{1}} & l_{12} \sqrt{\lambda_{2}} & \ldots & l_{1 m} \sqrt{\lambda_{m}} \\
l_{21} \sqrt{\lambda_{1}} & l_{21} \sqrt{\lambda_{2}} & \ldots & l_{2 m} \sqrt{\lambda_{m}} \\
\ldots & \ldots & \ldots & \ldots \\
l_{p 1} \sqrt{\lambda_{1}} & l_{p 1} \sqrt{\lambda_{2}} & \ldots & l_{p m} \sqrt{\lambda_{m}}
\end{array}\right]
\end{gathered}
$$

Factor loading is used to estimate the correlation coefficient between the observed variables. The load of common factors on each variable has little difference, so we cannot clearly explain the meaning of every common factor, and cannot name factors; therefore, we need a factor rotation. Factor rotation is equivalent to a reallocation of the same cumulative contribution rate on several common factors, under the premise of determined number of common factors, such that the load of each factor on variables tends to be more polarization, and substitutability of common factors to the variables is more explicit.

Factor rotation result can be seen from Table 3 . Factor $Z_{1}$ has significantly positive correlation with enterprise resource consumption and utilization, so $Z_{1}$ can be explained as enterprise resource possession and utilization factor. Factor $Z_{2}$ is highly correlated with environmental protection investment, social responsibility and technical knowledge, so $Z_{2}$ can be explained as the environment, responsibility and knowledge factor. Factor $Z_{3}$ is highly correlated with profitability, so $Z_{3}$ can be explained as profitability factor. Factor $Z_{4}$ has significantly positive correlation with the ability of management efficiency, so $Z_{4}$ can be explained as management efficiency factor. Factor $Z_{5}$ has significantly positive correlation with the creditor and debtor relationship, so $Z_{5}$ can be explained as the credit and debt factor. Factor $Z_{6}$ is highly relevant to internal growth ability, so $Z_{6}$ can be explained as internal growth factor. Factor $Z_{7}$ is highly relevant to external growth capacity, so $Z_{7}$ can be explained as external growth factor.

\subsubsection{Factor variables}

According to formula (7), the coefficient matrix has expressed the 7 common factors as a linear form of 26 basic variables indicators, the detail result can be seen from Table 4. 


$$
\left\{\begin{array}{c}
z_{1}=l_{11} x_{1}+l_{12} x_{2}+\cdots+l_{1 p} x_{p} \\
z_{2}=l_{21} x_{1}+l_{22} x_{2}+\cdots+l_{2 p} x_{p} \\
\vdots \\
z_{m}=l_{m 1} x_{1}+l_{m 2} x_{2}+\cdots+l_{m p} x_{p}
\end{array}\right.
$$

\subsubsection{Comprehensive Evaluation Model}

One common factor alone does not make a comprehensive evaluation of corporate green competitiveness. Thus using the variance contribution rate corresponding to each common factor as the weight, we calculated the comprehensive score of corporate green competitiveness as below.

$$
\text { Score }=\sum W_{j} Z_{j}
$$

\begin{tabular}{|c|c|c|c|c|c|c|c|}
\hline & $\mathrm{Z}_{1}$ & $\mathbf{Z}_{2}$ & $\mathbf{Z}_{3}$ & $\mathbf{Z}_{4}$ & $\mathbf{Z}_{5}$ & $\mathbf{Z}_{6}$ & $Z_{7}$ \\
\hline$X_{7}$ & .971 & & .184 & & & & \\
\hline$X_{12}$ & .966 & & .176 & & & & \\
\hline$X_{13}$ & .948 & -.171 & .124 & & & & \\
\hline $\mathrm{X}_{8}$ & .910 & .369 & .147 & & & & \\
\hline$X_{9}$ & .894 & .407 & & & & & \\
\hline $\mathbf{X}_{24}$ & .719 & -.225 & .134 & -.219 & .321 & .299 & .195 \\
\hline $\mathrm{X}_{10}$ & .125 & .899 & & & -.120 & & \\
\hline$X_{23}$ & & .867 & .174 & .197 & 238 & & \\
\hline$X_{25}$ & .206 & .864 & & & & .196 & \\
\hline$X_{2}$ & -.183 & .711 & -.301 & -.367 & & -.144 & .365 \\
\hline$X_{6}$ & -.220 & .664 & -.139 & .564 & & & .136 \\
\hline $\mathrm{X}_{1}$ & & .634 & & -.363 & .162 & .182 & -.522 \\
\hline$X_{26}$ & .175 & .622 & .230 & -.318 & & .271 & -.200 \\
\hline$X_{11}$ & .337 & -.537 & & & .295 & .514 & .242 \\
\hline$X_{17}$ & .205 & & .935 & . 169 & & & \\
\hline$X_{19}$ & .221 & & .927 & -.107 & .118 & .129 & \\
\hline$X_{18}$ & .102 & & .894 & . 198 & & .249 & \\
\hline$X_{4}$ & .211 & & 877 & .108 & -.117 & -.163 & \\
\hline$X_{14}$ & & & .226 & .919 & .131 & & -.178 \\
\hline$X_{3}$ & & -.103 & & .826 & & & -.100 \\
\hline$X_{15}$ & .135 & & & .641 & .579 & & .202 \\
\hline$X_{16}$ & & & -.245 & .271 & .786 & & -.143 \\
\hline$X_{5}$ & & -.127 & -.441 & .134 & -.760 & .109 & -.139 \\
\hline$X_{22}$ & & & .551 & & -.146 & .692 & \\
\hline$X_{20}$ & & .300 & & -.187 & -.552 & .575 & .185 \\
\hline$X_{21}$ & .294 & & -.125 & -.245 & & .181 & .823 \\
\hline
\end{tabular}

Table 3. Rotated Component Matrix 


\begin{tabular}{|c|c|c|c|c|c|c|c|}
\hline & $\mathbf{Z}_{1}$ & $\mathbf{Z}_{2}$ & $Z_{3}$ & $\mathbf{Z}_{4}$ & $\mathbf{Z}_{5}$ & $\mathbf{Z}_{6}$ & $\mathbf{Z}_{7}$ \\
\hline$X_{1}$ & .013 & .104 & -.048 & -.149 & . 161 & . 157 & -.409 \\
\hline$X_{2}$ & -.058 & .165 & .005 & -.106 & .017 & -.150 & .305 \\
\hline$X_{3}$ & .013 & -.009 & -.025 & .297 & -.068 & .041 & -.031 \\
\hline$X_{4}$ & -.011 & .001 & .274 & -.017 & -.118 & -.267 & .093 \\
\hline$X_{5}$ & .069 & -.049 & -.147 & .154 & -.367 & .133 & -.137 \\
\hline$X_{6}$ & -.055 & .164 & -.034 & .243 & -.060 & .031 & .179 \\
\hline$X_{7}$ & .195 & -.008 & -.010 & .001 & -.049 & -.083 & -.012 \\
\hline$X_{8}$ & .182 & .062 & -.026 & .019 & -.031 & -.057 & -.035 \\
\hline$X_{9}$ & .186 & .066 & -.059 & .025 & -.030 & .009 & -.100 \\
\hline$X_{10}$ & .018 & .183 & .007 & .014 & -.044 & -.054 & -.004 \\
\hline $\mathrm{X}_{11}$ & .029 & -.104 & -.065 & .019 & .152 & .383 & .076 \\
\hline$X_{12}$ & .196 & -.022 & -.016 & .027 & -.050 & -.081 & -.014 \\
\hline $\mathbf{X}_{13}$ & .195 & -.049 & -.026 & .009 & -.041 & -.068 & -.001 \\
\hline$X_{14}$ & .010 & -.002 & -.011 & .321 & -.027 & .097 & -.083 \\
\hline $\mathbf{X}_{15}$ & -.008 & .051 & -.020 & .199 & .215 & .069 & .168 \\
\hline $\mathbf{X}_{16}$ & .011 & .006 & -.138 & .040 & .382 & .154 & -.159 \\
\hline$X_{17}$ & -.026 & -.005 & .243 & .013 & -.027 & -.066 & .039 \\
\hline$X_{18}$ & -.053 & .006 & .207 & .045 & .004 & .097 & .013 \\
\hline$X_{19}$ & -.028 & -.007 & .243 & -.093 & .040 & -.044 & .008 \\
\hline$X_{20}$ & -.026 & .056 & -.041 & .065 & -.220 & .386 & .112 \\
\hline$X_{21}$ & -.006 & .023 & .010 & -.029 & .011 & .044 & .570 \\
\hline$X_{22}$ & -.076 & .013 & .074 & .057 & -.041 & .463 & .005 \\
\hline$X_{23}$ & -.028 & .197 & .050 & .055 & .104 & -.069 & .121 \\
\hline$X_{24}$ & .113 & -.050 & -.039 & -.078 & .164 & .170 & .039 \\
\hline$X_{25}$ & .030 & .175 & -.064 & .018 & .027 & .152 & -.044 \\
\hline$X_{26}$ & .016 & .110 & .017 & -.091 & .011 & .151 & -.154 \\
\hline
\end{tabular}

Table 4. Component Score Coefficient Matrix

\subsection{Results}

The results for evaluating green competitiveness based on the empirical analysis above are presented in Table 5 , the column from $Z_{1}$ to $Z_{7}$ represent the sub-item score of green competitiveness, the column $Z$ represent the comprehensive score of green competitiveness

\subsubsection{Sub-item comparison}

In general, we can find that factor $Z_{1}, Z_{2}, Z_{3}$ and $Z_{4}$, have a significant effect on the green competitiveness for automotive enterprises. In $Z_{1}$, enterprise resource possession and utilization factor, we could found that SAIC has a good performance followed by BYD while there is a big difference in score between those two, though. The worst performance company in this dimension is the Ankai bus. Looking into $Z_{2}$, environment, responsibility and knowledge factor, which is also very important to enhance green competitiveness, the top five are BYD, Foton, Great Wall Motor, Changan and JMC while the weakest is China National Heavy Duty Truck. The top five performers in $Z_{3}$, profitability factor, are JMC, Weichai Power, Yutong Bus, Great Wall Motor and Xingma while the bottom is Yaxing bus. The leading five companies in $Z_{4}$, management efficiency factor, are JAC, Yutong, Foton, FAW Car and Jinglong while Dima is the last one of the list. The top five enterprises in $Z_{5}$, credit and debt factor are FAW, Haima, Xiali, Dongan Power and JAC while the lowest is Yaxing Bus. Looking into $Z_{6}$, internal growth factor, 
the top five are Changan, Ankai Bus, Great Wall Motor, Zhongtong Bus and Yutong Bus while the last one is Dongan Power. Finally in $Z_{7}$, external growth factors, Dongan, Dima, Yutong Bus, Ankai Bus and Yaxing BUS are the first five of the list while the last one is Xingma.

\begin{tabular}{|c|c|c|c|c|c|c|c|c|}
\hline Code & $Z_{1}$ & $Z_{2}$ & $Z_{3}$ & $\mathbf{Z}_{4}$ & $Z_{5}$ & $\mathbf{Z}_{6}$ & $\mathrm{Z}_{7}$ & $\mathbf{z}$ \\
\hline 600104 & 4.466 & -0.656 & 0.460 & 0.121 & -0.052 & -0.139 & 0.425 & 1.047 \\
\hline 002594 & 0.615 & 4.031 & -0.349 & -0.358 & -0.445 & -0.309 & -0.136 & 0.822 \\
\hline 600066 & -0.579 & -0.142 & 1.651 & 1.8142 & -0.108 & 0.738 & 0.951 & 0.479 \\
\hline 600418 & -0.120 & 0.154 & -0.346 & 2.4549 & 0.731 & -0.047 & 0.180 & 0.343 \\
\hline 000550 & -0.670 & 0.434 & 2.083 & 0.042 & 0.707 & -1.123 & 0.293 & 0.342 \\
\hline 601633 & -0.441 & 0.637 & 1.366 & -0.469 & -0.199 & 1.242 & 0.151 & 0.297 \\
\hline 600166 & 0.175 & 0.676 & -0.219 & 1.333 & -0.454 & 0.202 & -0.618 & 0.251 \\
\hline 000338 & -0.010 & 0.010 & 2.002 & -0.869 & -0.753 & -0.817 & 0.092 & 0.139 \\
\hline 000625 & 0.311 & 0.520 & -0.594 & -1.063 & 0.667 & 2.034 & -0.342 & 0.112 \\
\hline 000800 & 0.019 & -0.288 & -0.982 & 1.069 & 2.253 & 0.069 & -0.994 & 0.061 \\
\hline 000927 & -0.334 & 0.275 & -0.821 & 0.240 & 1.403 & -0.188 & 0.369 & 0.003 \\
\hline 000572 & -0.010 & -0.750 & -0.297 & -0.612 & 2.176 & 0.514 & 0.220 & -0.039 \\
\hline 000868 & -0.697 & -0.250 & 0.045 & 0.046 & -0.919 & 2.007 & 0.880 & -0.107 \\
\hline 600686 & -0.393 & -0.184 & 0.010 & 0.933 & -0.900 & -0.604 & 0.322 & -0.116 \\
\hline 600178 & -0.674 & 0.347 & -0.022 & -1.429 & 1.005 & -1.499 & 2.040 & -0.153 \\
\hline 600006 & -0.098 & -0.492 & -0.287 & -0.062 & 0.065 & -0.254 & 0.017 & -0.200 \\
\hline 000957 & -0.422 & -0.156 & -0.363 & -0.103 & -0.964 & 1.047 & 0.171 & -0.230 \\
\hline 600375 & -0.367 & -0.584 & 1.000 & -0.863 & 0.255 & -0.722 & -2.494 & -0.320 \\
\hline 600303 & -0.247 & 0.074 & -0.150 & -1.057 & -0.369 & 0.405 & -2.286 & -0.365 \\
\hline 000951 & 0.014 & -1.256 & 0.010 & 0.762 & -1.078 & -0.809 & -0.813 & -0.372 \\
\hline 600609 & -0.262 & -0.543 & -0.462 & -0.220 & -0.960 & 0.244 & -0.142 & -0.381 \\
\hline 600565 & 0.041 & -1.180 & -0.233 & -1.604 & -0.106 & 0.599 & 1.146 & -0.396 \\
\hline 600760 & -0.111 & -0.373 & -1.692 & 0.091 & -0.875 & -1.428 & -0.251 & -0.608 \\
\hline 600213 & -0.205 & -0.304 & -1.811 & -0.198 & -1.078 & -1.161 & 0.820 & -0.610 \\
\hline
\end{tabular}

Table 5. Green competitiveness score for China automotive enterprises

\subsubsection{Comprehensive comparison}

With above in-depth analysis and benchmark, we are able to conduct the comprehensive comparison in terms of evaluation score and ranking among those 24 sample firms. The result indicates that SAIC, BYD, Yutong Bus, JAC and JMC occupied the top positions with the respective score $1.047,0.822,0.479,0.343$ and 0.342 . The last performer of the list is Yaxing BUS with score -0.610 . The evaluation unveils the fact that SAIC has better performance in resources possession and utilization than other companies while those two areas have the higher weight in the evaluation index structure. But we could also realize that, however, SAIC has relatively poor behavior in terms of environment and knowledge factors where further action need to be taken so as to maintain the sustainable competitive advantages. For instance, more investment to the areas like environmental protection, social responsibility and knowledge development could be the future direction and focus of their long term strategy, on top of maintaining the current leading position in resources.

Another good performer is BYD who won the second position of the benchmark not only because it's excellent achievement on resources possession and utilization, but also the outstanding performance on environment, responsibility and knowledge than other 
competitors. The evaluation also suggests BYD could pay more attention on its profitability and management efficiency area as well as the growth factor, which might be the future direction of their tactics for maintaining the leading position.

\section{Conclusion}

By defining the green competitiveness of automobile enterprises, this paper proposes one framework with four dimensions which include environment, resources, capability and knowledge. The relationship among them has been revealed and in-depth analysis has been conducted with the sample of 24 listed automotive enterprises. Our research indicates that the factors like enterprise resources possession and utilization; environment, responsibility and knowledge; earning; management efficiency have significant effect on the green competitiveness for automotive enterprises.

With the current pressure from both environment and energy, this paper thinks that China automobile industry must take further action on corporate social responsibility. The regular evaluation of the green competitiveness could be one good measurable approach for the "Green Upgrade" of the whole industry. On the other hand, one of the challenges of this approach is how to rationally determine the weight of each index of the evaluation model we proposed in the paper. The model itself can get objective results based on the factor analysis method. Furthermore, the green corporate competitiveness is changing dynamically with the affection from many factors. In order to make sure we can get the reasonable and executable outcome, the evaluation index system itself needs to be updated and upgraded with the input and learning from the real market and practice.

\section{Acknowledgments}

This article is supported by "the Fundamental Research Funds for the Central Universities" (Approval No. 2014JBM045). We also would like to express our most sincere appreciation to reviewers.

\section{References}

Chen, H.X., Liu, D., \& Yuan, Y. (2013). Study on the Evaluation of Green Competitiveness under low-carbon Model: the angle of value Chain. Science \& Technology Progress and Policy, 2, 1-5 (in Chinese). 
Chen, H.X, Wang, J.M., \& Yin, D.R., (2009). The Evaluation on Green Competitiveness of Listed Companies in Jiangsu. Province, 2, 59-64 (in Chinese).

Hart, S.L., \& Ahuja, G. (1996). Does it pay to be green? An empirical examination of the relationship between emission reduction and firm performance. Business strategy and the Environment, 5(1), 30-37.

http://dx.doi.org/10.1002/(SICI)1099-0836(199603)5:1<30: :AID-BSE38>3.0.CO;2-Q

Li, Y.H., \& Ding, H.P. (2009). Green Competitiveness for Automotive enterprises is needed to be improved. China's national conditions and strength, 9, 57-58 (in Chinese).

Luthra, S., Kumar, V., Kumar, S., \& Haleem, A. (2011). Barriers to implement green supply chain management in automobile industry using interpretive structural modeling techniqueAn Indian perspective. Journal of Industrial Engineering and Management, 4(2), 231-357. http://dx.doi.org/10.3926/jiem.2011.v4n2.p231-257

Porter, M.E. (1991, April). Green Competitiveness. New York Times.

Porter, M.E., \& Van der Linde, C. (1995a). Green and competitive: ending the stalemate. Harvard business review, 73(5), 120-134.

Porter, M.E., \& Van der Linde, C. (1995b). Toward a new conception of the environmentcompetitiveness relationship. The Journal of Economic Perspectives, 9(4), 97-118. http://dx.doi.org/10.1257/jep.9.4.97

Russo, M.V., \& Paul, A.F. (1997). A resource-based perspective on corporate environmental performance and profitability. Academy of management Journal, 40,534-559. http://dx.doi.org/10.2307/257052

Trotta, M.G. (2010). Product Lifecycle Management: Sustainability and knowledge management as keys in a complex system of product development. Journal of Industrial Engineering and Management, 3(2), 309-322. http://dx.doi.org/10.3926/jiem.2010.v3n2.p309-322

Wernerfelt, B. (1984). A resource-based view of the firm. Strategic management journal, 5(2), 171-180. http://dx.doi.org/10.1002/smj.4250050207

Yuan, Y., Wang, J.M., \& Chen, H.X. (2009) Fuzzy Evaluation Model Based on Entropy Weight for Green Corporate Competitiveness Assessment. Commercial research, 6, 33-37(in Chinese).

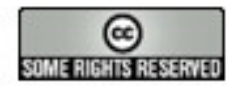

Article's contents are provided on a Attribution-Non Commercial 3.0 Creative commons license. Readers are allowed to copy, distribute and communicate article's contents, provided the author's and Journal of Industrial Engineering and Management's names are included. It must not be used for commercial purposes. To see the complete license contents, please visit http://creativecommons.org/licenses/by-nc/3.0/. 